Núria Casado-Gual

\title{
Exploring Old Age Through the Theatre: Three British Senior Theatre Companies
}

In a seminal article published in 2012, Valerie Barnes Lipscomb states that theatre studies can enrich the interdisciplinary study of ageing from at least three angles: as a way to analysis of the phenomenon of ageism, as an instrument to develop a narrative approach to ageing, and, finally, by taking into account the "performative" aspect of age and ageing, which the theatre is a natural means of expressing. A fourth perspective could regard the theatre as a potential source of exchange between academics, artists and the community, where meanings of age can be circulated and, consequently, an integrative, more complex, more enriching discourse on ageing can be constructed. In the light of these complementary perspectives, this paper explores the case of three British senior theatre companies that contribute to an enriching an "age-wise" conversation between the community and the artistic and academic domains. Our analysis is based on fieldwork conducted with the members of Ages and Stages (associated with the New Vic Theatre in Newcastle-under-Lyme, and closely related to Keele University), the Feeling Good Theatre Company (based at Leeds Playhouse) and the Elders Company (from the Royal Exchange Theatre in Manchester). We draw on recent developments in the increasingly interconnected fields of ageing and theatre studies to provide our theoretical framework (Basting 1998; Bernard et al. 2015; Lipscomb 2016; Mangan 2013), as well as data from participant observation, interviews conducted with the companies between May and July 2018, and some of their most recent scripts. The theatrical and social practices reflected in these testimonial and creative texts will be examined in order to observe the social practices these ensembles promote, and the cultural capital they generate for an anti-ageist society. As will be shown, through their emancipatory resort to the theatre both as a vehicle of self-expression and of social empowerment, Ages and Stages, Feeling Good, and The Elders Company can be aligned with an "affirmative" discourse of ageing (Sandberg 2013) which transcends the theatrical spaces they inhabit.

\section{Introduction}

The themes of ageing and, in particular, old age, have been part of the history of drama since its origins. However, critical attention to "ageing" within theatre 
studies is much more recent. This should not come as a surprise, considering the short trajectory of cultural gerontology as a field. Nonetheless, in her seminal book Aged by Culture, Margaret Morganroth Gullette used the theatre as an invaluable cultural frame to discuss age as a construct (2004), and even before then, Anne Davis Basting had explored the potential of theatre to undermine rigid views of ageing (1995, 1998). Since then, the connection between ageing or age studies and theatre studies has started to bear significant fruits through the academic work of other scholars like Michael Mangan (2013), Elinor Fuchs (2014, 2016), Valerie Barnes Lipscomb (2012, 2016), Bridie Moore (2014, 2018), and Sheila McCormick (2017), to name but a few. Inspiring theatre-based research projects, such as those conducted by Miriam Bernard and David Amigoni at Keele University (Bernard et al. 2015) or Anne Davis Basting at the University of Wisconsin-Milwaukee (Basting et al. 2016), and other academic initiatives around performance and age, such as monographic volumes (Lipscomb and Marshall 2010; Goldman and Switzky 2016; Bronk 2017; Gough and Nakajima 2019), or a working group led by Julia Henderson and Ben Gillespie within the Canadian Association of Theatre Research (2017-2020), have contributed to the growth of what is nowadays a thriving area of ageing studies.

In a pioneering article published in 2012, Lipscomb states that theatre can enrich the interdisciplinary study of ageing from at least three angles: it may be regarded as a source of analysis of the phenomenon of ageism; it can be considered another instrument to develop a narrative approach towards ageing; and, finally, it enhances the "performative" aspect of age and ageing, for which the theatre is a natural element of expression. As a complement to this triple perspective, a fourth view could be added, regarding theatre as a potential source of exchange, whereby meanings of age can be circulated and, consequently, an integrative discourse of ageing can be re-constructed. This fourth view is developed by different projects involving senior theatre, but is especially implemented by those that connect local communities with artistic and/or academic institutions. These fruitful interdisciplinary and transversal forms of collaboration have generated spaces of communication with a strong potential to overcome social barriers of different kinds, including those generated by agebased stereotypes. Nevertheless, as Lucy Munro and Miriam Bernard claim, "[d]espite many valuable critiques, the role that older people play in making theatre . . . is poorly understood" $(2015,61)$.

This chapter attempts to give academic consideration to senior theatre as a source of anti-ageist artistic practices and, consequently, of alternative conceptualisations of ageing. In particular, three British senior theatre companies that successfully create, to borrow Gullette's pun (2011), an “age-wise” circle of conversation between communities and their respective artistic or academic do- 
mains will be considered as case studies. These are "Ages and Stages”, the company formed within Bernard's age-and-theatre project with the New Vic Theatre from Newcastle-under-Lyme; Feeling Good Theatre Company, the long-lasting ensemble associated with Leeds Playhouse; and The Elders Company, based at the Royal Exchange Theatre in Manchester. A corpus of unpublished playscripts written by and/or for these companies serves as the basis for the study. These plays are examined through close readings developed within the framework of ageing studies, complemented with data from fieldwork conducted with the three companies in 2018. ${ }^{1}$ These data were mostly obtained through participant observation in workshop sessions of two of the three ensembles (Ages and Stages and The Elders Company), as well as through several semi-structured interviews with members of the three companies and their artistic directors.

The analysis of the companies' creative processes and their resulting playscripts, together with the consideration of testimonial narratives generated by our fieldwork, enhance the integrative, anti-ageist and developmental view of old age that these ensembles promote. In particular, the work produced by Ages and Stages, Feeling Good, and The Elders Company can be aligned with an "affirmative" discourse of ageing, in Linn Sandberg's terms (2013), which surpasses deeply-rooted cultural binaries of decline and success related to old age and youth, respectively. As will be shown, the dramaturgical mechanisms whereby the three formations re-present old age in their plays, as well as the artistic strategies through which those mechanisms are prompted and explored, foster a complex representation of later life that both counteracts and at the same time accepts and highlights the so-called challenges of age. The chapter is divided into two sections, which correspond to the double observation of the companies' dramaturgical and workshop methods. The conclusions of the study de-

1 I would like to thank Dr Mim Bernard, Dr David Amigoni, and Dr Dana Rosenfeld for their generous hospitality during my research stay at Keele University between May and June 2018, as well as the directors Jill Rezzano, Andy Barry, Nicky Taylor, Machteld De Ruyck, and the members of the three companies studied in this chapter, for having shared their work and experiences with me. Very especially, I am grateful to Jill and the members of Ages and Stages for having welcomed me in their rehearsals in the last term of their 2017-2018 season, and having made me feel part of the company for a while. Their work will remain a source of inspiration for me, both as an academic and theatre maker. I would also like to thank the José Castillejo mobility programme for young researchers of the Spanish Ministry of Education, which allowed me to conduct this study; Dr Andrea von Hülsen-Esch, for having invited me to the international symposium in cultural gerontology she organised in Hanover in 2018, where I presented the first results of my research on senior theatre; my colleagues from the Canadian Association in Theatre Studies, with whom I shared an analysis of my fieldwork at the 2019 conference in Vancouver; and Ms Inesa Shevchenko, for her help in the transcriptions of the interviews. 
scribe the companies' particular ways of using theatre as a vehicle of self-expression and social empowerment for the anti-ageist agenda they all have in common, an ideological feature that mainstream theatre is only beginning to display.

\section{Re-Presenting Old Age: Dramaturgical Mechanisms for an Anti-Ageist Theatre}

In an extensive review of the cultural value derived from experiences of theatremaking by older people, Bernard and Michelle Rickett contend that, with very few exceptions, "the aesthetic quality of older people's drama" and the "transformative potential of devised productions, derived from co-constructed research with older people" remains under-researched (2016, 22-23). Indeed, the scripts that result from some of the workshops and co-devised work of the companies considered in this chapter offer an interesting source from which both their theatrical creativity as well as the narrative of age that results from it can be observed. Significantly, their plays tend to avoid, or even explicitly confront, the "declinist" view of old age that is found at the heart of ageism and which, according to Elinor Fuchs, is mostly generated by the predominantly peak-andfall structures of Aristotelian/dramatic/naturalistic dramaturgical models (2014, 72; 2016, 153). Working within the incipient interconnection between theatre and ageing studies, Fuchs has initiated an inspiring theoretical framework whereby lifecourse theory is interwoven with the creative and ideological implications of Brechtian theatre. In her theatrical theory of age, Fuchs recognises the capacity of Brechtian or epic theatre to promote a developmental view of ageing, and so contest what she denominates "the Sublime of Age", namely, "a visceral horror of physical decrepitude" (2014, 70). This declinist "sublime" corresponds to a conceptualisation of age that the senior theatre companies observed here clearly resist through their epic, anti-Aristotelian scripts. Indeed, Ages and Stages, Feeling Good Company, and The Elders Company clearly promote a Brechtian approach to theatre whereby an open and, hence, developmental model of theatre-and-ageing, understood in Fuchs' terms, is generated. Either as an explicit or implicit response to the mis-representation of older people in the mainstream stage, which the members of Feeling Good and Ages and Stages acknowledge in their focus-groups discussions (Ages and Stages 2018; Feeling Good 2018b), the texts in which the performers of these companies tell their own stories broaden the narrative of old age through the use of eclectic dramaturgical devices. 
The anti-decline discourse of active ageing that underlies their creations is made explicit in the founding documents of the Feeling Good Company, which is defined as "a group of older people dedicated to challenging the negative stereotyping that often surrounds the older generation" through the presentation of "real and positive images of later life" in their shows (Dobson 2018). Over their eighteen-year history, Feeling Good has produced successful shows for Leeds Playhouse and other community centres in West Yorkshire. The active-ageing ideology of their original, often commissioned, pieces entails an emphasis on the older person's capacities, and places the ageing body centre-stage as a source of ongoing physical and social activity. This is clearly the case for Active Ageing (Feeling Good 2018a), a piece that highlights the negative effects of passive lifestyles, and connects them with the characters' chronic ailments. It is also reflected in The Look of Love (Feeling Good 2013b), in this case through the show's physical-theatre approach, which enhances the performers' body as a source of beauty and places the actors' emotional life centre-stage. In a similar vein, Benchmark (Feeling Good 2013a) exploits the polysemic power of the theatrical sign (an element of the setting, in this case) to generate a palette of characters who reflect "an often unseen positive image of ageing" (West Yorkshire Theatre 2013). While using a clichéd image of old age (namely, that of ageing characters sitting on a bench), the piece subverts declinist views of later life through its dialogues and situations, in which humour plays an important role. Indeed, comedy is the main genre and acting register whereby the members of this company convey their anti-decline narrative of old age. At the same time, their scripts avoid the superficial optimism of the successful-ageing discourse by resorting to self-parody in order to integrate negative aspects of ageing, such as social isolation or fragility, without making them the sole defining features of the experience of growing older. A clear example of this is the sequence of comic sketches in Doorstep Crime (Feeling Good 2014), through which the company shows different scams that older people who live by themselves could fall victim to. The comic twist is often found at the end of every sketch, where the performers empower their older viewers to respond to this extended form of crime by increasing their awareness of its methods.

At Manchester's Royal Exchange Theatre, the Elders Company and their artistic director Andrew Barry have developed a rich repertoire of adaptations and also devised plays that draw from different theatrical styles. In one of their most recent original shows, Moments that Changed Our World (Barry 2018a), physical and visual theatre are combined with reminiscence theatre to convey a collective "life review" that is inextricably related to the performers' current age identities. Through the text's fusion of personal and public moments of transition, the show interweaves the different life stories of the cast with the issues of gender, 
sexuality, class, and race that intersect with the performers' experience of ageing. To mention an example, Graham develops a life narrative in which his homosexuality becomes a source of marginalisation as well as of identity. At the same time, he defines himself as a "baby-boomer" (Barry 2018a, 6), and, as such, his "coming-out" story is inextricably bound up with and conditioned by his generational identity. The other testimonial stories of the play complete the theatrical collage of personal experiences of ageing through the lens of identity politics, and all of them culminate in the acquisition of age-related identities as pensioners (Barry 2018a, 9), grandparents (Barry 2018a, 11), and, in all cases, theatre artists (Barry 2018a, 12). Interestingly, the participants' varied late-life self-definitions refer to the experience of growing older as a continuous process of development and self-realisation in which past and present become conflated and, in this way, a more complex sense of self emerges out of this new timeframe. As Brenda vividly puts it when re-enacting her debut as a senior performer: "That was when I knew. THIS IS ME! THIS IS WHO I AM! This is where I am meant to be. THAT WAS MY MOMENT!” (Barry 2018a, 12). Through its multi-temporal angles, and its amalgam of class-, gender-, sexuality-, race-, and age-related stories, The Elders' latest piece generates a polyhedral "age autobiography”, in Gullette's terms $(2004,26)$, in which “[a]ging becomes maturation, change, history -more complex than a simple minus or a plus" (2004, 10). At the same time, by using an epic montage structure that highlights "moments" rather than a sequential narrative, the piece enhances the multi-dimensional experience of time that becomes more evident in later stages of life (Baars 2012), while at the same time acknowledging the various ages that are contained within the performers' testimonial stories. On the whole, Moments that Changed Our World is an "age-defying" piece, to use a term from Barry's evaluation report for this piece (2018c, 13), insofar as it challenges reductive assumptions about old age that some of the performers themselves had internalized when approaching the retirement age - "I'm not one of them!", claimed Brenda, in her ironic recollection of her 60th birthday (Barry 2018a, 9). But, more than "age-defying”, it is an age-defining show, inasmuch as it stresses the complex age-identity resulting from the accumulation of perspectives and experiences over time.

Under the direction of Jill Rezzano, since its creation in 2009, Ages and Stages has also developed dramaturgies with an overtly anti-ageist orientation. Resulting from a research project co-led by Bernard at Keele University and The New Vic Theatre in Newcastle-under-Lyme, one of the distinctive features of this company's theatrical style is the frequent use of audience participation. As expressed in one of their shows, significantly entitled Live Age Conversation: "We believe that what you have to say, what audiences have to say is as important as what is said on stage" (Rezzano 2012, 14). Directly related to the Forum- 
theatre techniques of their training, their plays frequently break the fourth wall to ask audience members about the meanings certain scenes bear for them. Moreover, some of their plays involve collaborations with the New Vic's young company, which fosters intergenerational exchange on and off the stage. The intergenerational piece Our Age, Our Stage (Rezzano 2012), the first in the company's history, combines documentary drama, reminiscence drama, and an openended, forum-theatre structure that emphasises the cultural value that the Old and New Vic Theatres have had for several generations in their respective communities. Live Age Conversation (Rezzano 2012), which similarly pays tribute to the city of Stoke-on-Trent, where the Old Vic theatre was built, uses maps as symbolic props, and associates the cultural and historical heritage of Stoke with the actors' bodies, experiences, and words, as well as with those of the audience. In Out of the Box (Rezzano n.d.), which uses a TV contest as dramaturgical framework, the "viewers" of the show are invited to think of art and culture as sources of (self)-transformation for all ages (Rezzano n.d., 9). Happy Returns is another inter-generational play that illustrates the effects of ageism across the lifespan (Rezzano 2013, 17). The play, which once again creates a space of exchange among different generations in the audience (Rezzano 2013, 17), finishes with an open-ended scene in which an exchange of birthday presents and cards helps the audience examine and question "age appropriateness" (Rezzano 2013, 19). The final sequence concludes with an invitation to the audience members to say what birthday present they would like to receive in the future (Rezzano 2013, 20). Significantly, this ending enables the visualisation of the viewers' older selves as having specific desires and needs that may differ, or not, from their current ones, while at the same time presenting age as a "performative" in which the possibility to "do / imagine / write" one's age-identity remains both personal and open at all stages.

\section{Rehearsing Age: The Unlimited Re-Creation of Later-Life}

Through their rich dramaturgical forms and age narratives, the shows devised or co-devised by the three companies render old age a cultural engine, more than a receptacle. This provides an interesting contrast to the predominant idea that older people play an important role in the theatre only as an predominant component of its audiences. If, as maintained by Bernard and Rickett (2016, 23), further research into the aesthetic and transformative power of senior theatre "could enhance our understanding of the cultural value provided by older peo- 
ple, rather than just the value they derive from their participation”, the image of older people as potential theatre practitioners and, therefore, as significant generators of culture, would pave the way for a truly anti-ageist theatre.

As shown in interviews and focus-group discussions with the participants and their directors, these companies's shows are transformative for those involved in their own right. Nonetheless, the creative processes from which they emerge also need to be examined, in order to understand how far these plays' integrative narratives of age continue to circulate beyond their theatrical domain. Through the conversations they generate on and beyond the stage, the three companies promote a developmental view of old age in which late-life creativity plays a key role. In her theatrical theory of age, Fuchs recognises the capacity of Brechtian or epic theatre to promote a developmental view of ageing (2014, 70). Indeed, the companies considered in this paper clearly promote a Brechtian approach to theatre to generate an anti-declinist view of old age. To start with, the members of Ages and Stages, the Elders Company, and Feeling Good are all active participants in seasonal rehearsal processes that are not necessarily aimed at devising a specific show. The sense of openness favoured by the companies' rehearsal processes reinforces a positive, dynamic view of later-life creativity, since every session paves the way for a new discovery, challenge, or lesson, for which performers are ready.

The rehearsal methods adopted by these companies are also Brechtian in the way they use anti-naturalistic aesthetics and, hence, allow for "anything to happen" in their minimalistic mise-en-scènes. This includes the emancipation of the ageing body itself from the constraints of the realist scene. Naturalistic drama tends to emphasise the actor-characters" "chronological" and "social" ages, to the detriment of their "personal” age, to use Kathleen Woodward's understanding of the age construct $(1991,149)$. By contrast, in the anti-naturalistic settings employed by these companies, the actors' bodies may express the performers' "personal age" and, in this way, their characters become simultaneously "ageless" and "multi-aged", depending on the situation. Especially through the frequent use of improvisation as both creative and training device, social and cultural readings of the actors' chronological and biological ages are often ignored and/or even transgressed. The Elders Company and, particularly, Ages and Stages, play with the life cycle as if it was a non-linear, malleable continuum of stages, whose associated masks actors can freely put on or remove. On the other hand, the members of Feeling Good prefer to align their chronological age with that of their characters, enhancing, in this way, the value of their later years (Feeling Good 2018b). In fact, the company's first name was "Act Your Age", which was also the title of their first show, intended to revalidate what it means to be an older person. However, they also defy essentialist 
views of old age through the stories they focus on, and equally resort to the bare stage as a source of dialectic drama.

Through the companies' dramaturgical openness and epic theatricality, participants co-construct a critical artistic language whereby they may regard themselves in both the first- and the third-person, very much in the way that Fuchs, drawing from Brecht and the age critic Kathleen Woodward, defines the "estraged" or "detached" form of subjectivity that is produced in later life (2016, 144). This "double gaze”, or "double consciousness", which Michael Mangan identifies as part and parcel of the art of acting as well as of the process of ageing $(2013,37)$, is inherent in the creative laboratory format adopted by the three companies. The "double form of being" implicit in acting and in the experience of ageing enables the members of the three groups to integrate the process of growing older within an artistic medium that can also be extended to other members of the community. As Rezzano argue (2018), the rehearsal period of Ages and Stages keeps the participants' creative flow open, and simultaneously prepares them to become enthusiastic co-leaders of outreach workshops. In a similar vein, the members of Feeling Good contribute to "Heydays" (Leeds Playhouse 2018), the creative programme for people over fifty-five run by Leeds' Playhouse (Feeling Good 2018b). Likewise, the actors of the Elders Company "graduate" from the company's training programme after a year of membership, becoming collaborators with the company's new members (Barry 2018b).

The personal and critical interpretations of old age that result from these companies' creative work and their related forms of social engagement are clearly reflected in personal interviews and focus-group discussions. Both participants and directors re-conceptualise old age in three main ways: a) as a phase in which a new kind of creativity can emerge, b) as a stage of self-validation, and c) as a source of positive change. The alternative narrative they co-construct through these views can be directly related to Sandberg's conceptualisation of “affirmative ageing”, in that it is derived from the practitioners' direct knowledge and experience with their own acting/ageing bodies, whose "material specificities" are not denied, but rather "understood as possessing force and agency to also shape subjectivity and society” $(2013,17)$. The participants' corporeal, personal, and social engagement with the theatre enables them to define their later-life creativity in anti-declinist terms, as therapeutic (Ages and Stages 2018), empowering (Feeling Good 2018b) and closely connected with physical manifestations of quality of life (Ages and Stages 2018) - and, more significantly, as freer and braver (Ages and Stages 2018; Barry 2018b), more focused on the present moment (Barry 2018b), more complex in terms of skills and philosophical in inclination (Ages and Stages 2018), and more critical (Feeling Good 2018b), especially in comparison with creative work from earlier life stages. At 
the same time, the creative opportunities offered by the companies' projects inform a predominantly positive perception of old age as an "equally enjoyable" life stage in comparison to other phases of life, comparable to "the best job [one could] ever ha[ve]", in which new forms of "fulfilment" are found (Ages and Stages 2018). Even the most negative response offered by one of the interviewees ("I have found this part of my life the worst time ever. From the age of seventy onwards, I've struggled every bit of the way") is also positively connected with the theatre: the interviewee says that she joined the company to overcome her personal difficulties. Finally, the participants' integrative views of old age clearly present the ageing body as a continuous agent of "difference". Such “difference”, as Sandberg interprets it, borrowing from Deleuze $(2013,19)$, is not a form of alterity, but, on the contrary, a source of positive change.

Both participants and directors are aware of the counter-model that their projects represent, not only in the spaces of performance in which they intervene but also within the broader context of theatre. One of the actresses of Ages and Stages, expressing the group's general opinion, would like to "get away from the standard typical old person and old person's problems” that, all too often, are associated with tragic and biased renderings of dementia. Similarly, the members of Feeling Good and Ages and Stages describe the personal and social barriers they break down through their community projects, including reductive views of old age. All three artistic directors allude to the anti-ageist ideology underlying many of their artistic strategies and practices, such as developing a digitalised narrative of ageing for a particular show (Barry 2018b), or making it a basic principle that participants lead or co-lead their own work (Rezzano 2018; Ruyck 2018).

\section{Conclusions}

The creative processes of three senior companies writing, producing, and promoting theatre in the UK today constitute important anti-ageist practices, both through the anti-decline and diverse image of old age offered in their workshops, and the sense of agency they confer - not only to their performers, but to their audiences and workshop participants. Having considered their "epic" rehearsal methods, their eclectic dramaturgical styles, and the age narratives their work processes produce, we argue that Feeling Good, The Elders Company, and Ages and Stages offer diverse models of age-performativity and age-ideology, where old age is presented as a dynamic category. At the end of our research, the three ensembles continued to extend the circle of their re-presentation of age to more sectors of the local community, by recruiting new members (Elders 
Company), producing new intergenerational shows with participants of different ages and social backgrounds (Feeling Good), and organising an annual arts festival in which ageing is foregrounded as a source of creativity (Ages and Stages).

It is worth noting that the affirmative model of ageing favoured by these ensembles contrasts significantly with the predominance of the narrative of decline on the mainstream stage (Mangan 2013; Bronk 2017), where, as Gullette contends, being "the oldest person in the dramatis personae is suddenly glued to cognitive weakness” (2016, 231). As shown by Lipscomb, the dialogue between research, professional arts, and community theatre is difficult, but not impossible (2016; and the theatre (in both professional and non-professional contexts) still has much to offer in the exploration of the intricacies of ageing and in the circulation of meanings ascribed to old age. In considering these three companies here, we have attempted a modest contribution to an field, one that invites further research into different socio-cultural contexts in which senior theatre is thriving, and which, hopefully, will generate more "age-wise" representations and conversations.

\section{Works cited}

Ages and Stages. Interviews and Focus Groups with Núria Casado-Gual. Newcastle-under-Lyme: New Vic Theatre, 2018.

Barry, Andrew, and The Elders Company. Moments that Changed Our World (Unpublished manuscript). Manchester: Royal Exchange Theatre, 2018a.

Barry, Andrew. Interview with Núria Casado-Gual. Manchester: Royal Exchange Theatre, 2018b.

Barry, Andrew. Moments that Changed Our World (Evaluation report). Manchester: Royal Exchange Theatre, 2018c.

Baars, Jan. Aging and the Art of Living. Baltimore: The Johns Hopkins University Press, 2012.

Basting, Anne Davis. "The Stages of Age: The Growth of Senior Theatre." The Drama Review 39.3 (1995): $112-130$.

Basting, Anne Davis. The Stages of Age: Performing Age in Contemporary American Culture. Ann Arbor: University of Michigan Press, 1998.

Basting, Anne Davis. Forget Memory: Creating Better Lives for People with Dementia. Baltimore: John Hopkins University Press, 2009.

Basting, Anne Davis, Maureen Towey, and Ellie Rose. Eds. The Penelope Project: An Arts-Based Odyssey to Change Elder Care. lowa City: The University of lowa Press, 2016. Bernard, Miriam. "Theatre and Ageing." Routledge Handbook of Cultural Gerontology. Eds. Julia Twig, and Wendy Martin. London and New York: Routledge, 2015. 61-68.

Bernard, Miriam, Michelle Rickett, David Amigoni, Lucy Munro, Michael Murray, and Jill Rezzano. "Ages and Stages: The Place of the Theatre in the Lives of Older People." Ageing \& Society 35.6 (2015): 1119-1145. 
Bernard, Miriam, Michelle Rickett, David Amigoni, Lucy Munro, Michael Murray, Jill Rezzano et al. "The Place of Theatre in Representations of Ageing." The New Dynamics of Ageing (Vol. II). Ed. Alan Walker. Bristol: Policy Press, 2016. 285-306.

Bernard, Miriam, and Michelle Rickett. "The Cultural Value of Older People's Experiences of Theatre-Making." The Gerontologist 7.2 (2016): 1-26.

Black, Kathy, and Valerie Barnes Lipscomb. "The Promise of Documentary Theatre to Counter Ageism in Age-Friendly Communities." Journal of Aging Studies 42 (2017): 32-37.

Bronk, Katarzyna. Autumnal Faces: Old Age in British and Irish Dramatic Narratives. Oxford: Peter Lang, 2017.

Dobson, Val. Feeling Good Theatre Company (Informative leaflet). Leeds: Leeds Playhouse, 2018.

Feeling Good Theatre Company. Benchmark (Unpublished manuscript). Leeds: Leeds Playhouse, 2013a.

Feeling Good Theatre Company. The Look of Love (Unpublished manuscript). Leeds: Leeds Playhouse, 2013b.

Feeling Good Theatre Company. Doorstep Crime (Unpublished manuscript). Leeds: Leeds Playhouse, 2014.

Feeling Good Theatre Company. Active Ageing (Unpublished manuscript). Leeds: Leeds Playhouse, 2018a.

Feeling Good Theatre Company. Focus Group with Núria Casado-Gual. Leeds: Leeds Playhouse, 2018b.

Fuchs, Elinor. "Estragement.” Performance Research 19.3 (2014): 69-77.

Fuchs, Elinor. "Rehearsing Age." Modern Drama 59.2 (2016): 143-154.

Goldman, Marlene, and Lawrence Switzky. "Modern Drama, Ageing, and the Life Course.” Modern Drama 59.2 (2016): 135-142.

Gough, Richard, and Nanako Nakajima. "Performance Research." On Ageing (\& Beyond) 24.3 (2019).

Gullette, Margaret Morganroth. Aged by Culture. Chicago: University of Chicago Press, 2004.

Gullette, Margaret Morganroth. Agewise: Fighting the New Ageism in America. Chicago and London: University of Chicago Press, 2011.

Gullette, Margaret Morganroth. "Politics, Pathology, Suicide, and Social Fates: Tony Kushner's The Intelligent Homosexual's Guide to Capitalism and Socialism with a Key to the Scriptures." Modern Drama 59.2 (2016): 231-248.

Leeds Playhouse. Heydays (Theatre leaflet). Leeds: Leeds Playhouse, 2018.

Lipscomb, Valerie Barnes. “'The Play's The Thing': Theatre as a Scholarly Meeting Ground in Age Studies." International Journal of Ageing and Later Life 7.2 (2012): 117-141.

Lipscomb, Valerie Barnes. Performing Age in Modern Drama. New York: Palgrave Macmillan, 2016.

Lipscomb, Valerie Barnes, and Leni Marshall. Eds. Staging Age: The Performance of Age in Theatre, Dance, and Film. New York: Palgrave Macmillan, 2010.

Mangan, Michael. Staging Ageing: Theatre, Performance and the Narrative of Decline. Bristol: Intellect, 2013.

McCormick, Sheila. Applied Theatre: Creative Ageing. London: Methuen, 2017.

Moore, Bridie. Depth, Significance, and Absence: Age-Effects in New British Theatre. http:// ageculturehumanities.org/WP/depth-significance-and-absence-age-effects-in-new-britishtheatre/. Age, Culture, Humanities 1, 2014 (21 February 2019). 
Moore, Bridie. Effects, Metaphors and Masks: Reading and Doing Age in Contemporary British Theatre (Unpublished PhD thesis). University of Sheffield, 2018.

Rezzano, Jill, and Ages and Stages Company. Live Age Conversation (Unpublished manuscript). Newcastle-under-Lyme: New Vic Theatre, 2012.

Rezzano, Jill. Our Age, Our Stage (Unpublished manuscript). Newcastle-under-Lyme: New Vic Theatre, 2012.

Rezzano, Jill. Happy Returns (Unpublished manuscript). Newcastle-under-Lyme: New Vic Theatre, 2013.

Rezzano, Jill. Interviews with Núria Casado-Gual. Newcastle-under-Lyme: New Vic Theatre, 2018.

Rezzano, Jill. Out of the Box (Unpublished manuscript). Newcastle-under-Lyme: New Vic Theatre, n.d.

Ruyck, Machteld De. Interview with Núria Casado-Gual. Leeds: Leeds Playhouse, 2018.

Sandberg, Linn. "Affirmative Old Age: The Aging Body and Feminist Theories of Difference." International Journal of Aging and Later Life 8.1 (2013): 11-40.

West Yorkshire Theatre. Open Season (Theatre leaflet). Leeds: Leeds Playhouse, 2013.

Woodward, Kathleen. Aging and Its Discontents. Bloomington and Indianapolis: Indiana University Press, 1991. 
